\section{TOXAEMIA OF PREGNANCY}

\section{SOME EPIDEMIOLOGICAL RELATIONSHIPS TO NEPHRITIS, RHEUMATIC FEVER, AND STILLBIRTH}

BY

\section{T. W. BUCHAN, M.B., F.R.F.P.S., D.P.H.}

A recent study of the effect of cortisone in toxaemia of pregnancy (Moore et al., 1951) suggests that this condition is related to rheumatic fever and nephritis, and it is of interest to explore the possible relationship by investigating the regional distribution of the maladies concerned by making use of the relevant mortality'statistics as provided by the Registrar-General of England and Wales. Stillbirth is a related problem, a proportion of stillbirths being directly attributable to eclamptic and nephritic toxaemia. Data on this aspect are therefore included in the present study.

\section{Regional Variations}

In a previous paper (Buchan, 1950a) the closely analogous distribution of eclampsia and stillbirth was noted. Our concern now is with the regional variations of rheumatic fever, acute nephritis, scarlet fever, puerperal sepsis, stillbirth, and eclampsia. There is considerable evidence that rheumatic fever and acute nephritis represent an allergic response to invasion by a haemolytic streptococcus, and it is convenient to begin the present study by inquiring whether mortality from these two diseases shows any correspondence in regional distribution.

Their mortality in England and Wales cannot be directly investigated because before 1940 deaths were not tabulated under these headings on a regional basis in the Registrar-General's Statistical Review. Even in 1940 and subsequent years, of these two diseases, deaths from rheumatic fever alone are so classified, and then not in age groups, so only crude rates can be calculated. Crude rates, however, are not satisfactory indices of mortality on account of the differing age constitution - of the relevant populations, but in seeking to investigate the regional distribution of rheumatic fever there are good reasons for using as indices the death rates in the younger age groups from the causes included under the broad heading of "heart diseases." Knowelden (1949) shows that in the 5-14 age group over $90 \%$ of the deaths under this large heading are almost entirely rheumatic in origin, and in the 15-24 age group, $86 \%$; accordingly, it is reasonable to use such age-group death rates as indices of mortality from rheumatic fever. Similar data are available under the heading of "nephritis."

Tabulation of the deaths for the years 1932-7 shows that at ages $5-14$ years $46 \%$ of deaths debited to this cause fell to the title " acute nephritis," and at ages 15-24 years $27 \%$ were so classified. Of those falling to chronic nephritis, the corresponding figures were $43 \%$ and $53 \%$, but it is reasonable to assume that, in these age groups, deaths so assigned were almost all secondary to acute nephritis. The death rates under nephritis in these two age groups may therefore be taken as valid indices of mortality from acute nephritis.

The death rates for the years 1932-7 for heart disease and nephritis respectively in those two age groups in each of the twelve main regions of England and Wales are contained in Table $I$. The coefficients of correlation between the rates for the two diseases in the same age groups are also given (Table II). The coefficient between

TABLE I.-Regional Death Rates in 1932-7 in England and Wales

\begin{tabular}{|c|c|c|c|c|c|c|c|c|}
\hline & \multicolumn{5}{|c|}{ Per Million Living } & \multicolumn{2}{|c|}{$\begin{array}{c}\text { Per } 1,000 \\
\text { Total } \\
\text { Births }\end{array}$} & \multirow{3}{*}{$\begin{array}{c}\begin{array}{c}\text { Per } \\
\text { Millior } \\
\text { Living }\end{array} \\
\text { Can- } \\
\text { cer† } \\
15-24 \\
\text { Years }\end{array}$} \\
\hline & \multicolumn{2}{|c|}{ Heart Disease } & \multicolumn{2}{|c|}{ Nephritis } & \multirow{2}{*}{$\begin{array}{l}\text { Scarlet } \\
\text { Fever } \\
0-4 \\
\text { Years }\end{array}$} & \multirow{2}{*}{$\begin{array}{l}\text { Puer- } \\
\text { peral } \\
\text { Sep- } \\
\text { sis }\end{array}$} & \multirow{2}{*}{$\begin{array}{l}\text { Still- }- \\
\text { birth }\end{array}$} & \\
\hline Kegr & $\begin{array}{l}5-14 \\
\text { Years }\end{array}$ & \begin{tabular}{|l|}
$15-24$ \\
Years
\end{tabular} & $\begin{array}{l}5-14 \\
\text { Years }\end{array}$ & $\begin{array}{l}15-24 \\
\text { Years }\end{array}$ & & & & \\
\hline & & 2 & 3 & 4 & 5 & 6 & 7 & 8 \\
\hline e & 102 & 189 & 28.5 & $60 \cdot 2$ & 83 & $1 \cdot 27$ & 32 & 44 \\
\hline 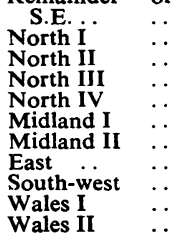 & $\begin{array}{r}60 \\
121 \\
116 \\
130 \\
136 \\
101 \\
101 \\
59 \\
65 \\
167 \\
95\end{array}$ & \begin{tabular}{|l|l}
121 \\
252 \\
224 \\
252 \\
254 \\
218 \\
195 \\
127 \\
113 \\
335 \\
199
\end{tabular} & $\begin{array}{l}34 \cdot 5 \\
21.3 \\
31.6 \\
50.6 \\
31.6\end{array}$ & \begin{tabular}{|l|}
44.0 \\
77.6 \\
61.5 \\
82.5 \\
80.1 \\
75.0 \\
$80 \cdot 1$ \\
57.8 \\
44.8 \\
95.2 \\
93.3
\end{tabular} & $\begin{array}{r}54 \\
264 \\
74 \\
135 \\
94 \\
70 \\
54 \\
31 \\
40 \\
114 \\
76\end{array}$ & & $\begin{array}{l}40 \\
41 \\
38 \\
40 \\
55 \\
52\end{array}$ & $\begin{array}{l}43 \\
41 \\
45 \\
44 \\
43 \\
52 \\
40 \\
41 \\
45 \\
36 \\
42\end{array}$ \\
\hline
\end{tabular}

* For the geographical constitution of the regions, see the Registrar General's Statistical Revizw, any recent issue.

$\dagger$ These rates are included as a check. They do not show a significant degree of correlation with any of the other rates.

TABLE II.-Correlation Coefficients of Regional Death Rates in Table I

\begin{tabular}{|c|c|c|c|c|c|}
\hline $\begin{aligned} \mathrm{r} 13= \\
\mathrm{HS}\end{aligned}$ & $\underset{\mathrm{HS}}{\mathrm{r} 24=}$ & $\mathrm{r} 35=\underset{\mathrm{HS}}{+0 \cdot 71}$ & $\mathrm{r} 45=\underset{\mathrm{NS}}{+0.41}$ & $\mathrm{r} 56=\underset{\mathrm{S}}{+0 \cdot 65}$ & $\mid \begin{array}{c}\mathrm{r} 67= \\
\mathrm{HS}\end{array}$ \\
\hline $\begin{array}{c}\mathrm{r} 15=+0.54 \\
\mathrm{NS}\end{array}$ & $\begin{array}{c}r 25=+0 \cdot 58 \\
S\end{array}$ & $\begin{array}{c}\mathrm{r} 36=+0 \cdot 74 \\
\text { HS }\end{array}$ & $\begin{array}{c}\mathrm{r} 46=+0.73 \\
\mathrm{HS}\end{array}$ & $\begin{array}{c}\mathrm{r} 57=+0.60 \\
S\end{array}$ & \\
\hline $\begin{array}{c}\mathrm{r} 16= \\
\mathrm{HS}\end{array}$ & $\begin{array}{c}\mathrm{r} 26=+0.82 \\
\mathrm{HS}\end{array}$ & $\mathrm{r} 37=+{ }_{\mathrm{S}}^{0.67}$ & 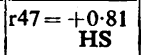 & & \\
\hline $7=\underset{\mathrm{S}}{+0 \cdot 66}$ & $\mathrm{r} 27=\underset{\mathrm{S}}{+0.69}$ & & & & \\
\hline
\end{tabular}

The first two numbers refer to columns in Table I-for example, r13 means coefficient of correlation of columns 1 and 3 . HS = Highly significant, implying a chance probability less than 0.01 . NS = Not significant, implying a chance probability greater than $0 \cdot 05$. $S=$ Significant, implying a chance probability between these values.

the two series of rates in the 5-14 year age group is +0.87 and in the 15-24 year age group it is +0.80 . These values are highly significant and provide evidence of a direct relationship between the regional distribution of mortality from rheumatic fever and acute nephritis.

\section{Some Comparisons}

The regional variations of rheumatic fever and acute nephritis may now be compared with those of the two streptococcal infections chosen, scarlet fever and puerperal sepsis (Tables I and II). With the use of the first of the two indices for rheumatic fever-namely, heart disease mortality at 5-14 years-the correlation $(+0.54)$ with the scarlet fever death rates at $0-4$ years is just short of the arbitrary level of statistical significance. With use of the second index (heart disease mortality at 15-24 years) the coefficient is +0.58 , and is significant. Taking now the nephritis rates, we find that in the 5-14 age group the correlation $(+0.71)$ with scarlet fever is highly significant, but in the 15-24 age group for nephritis it is not significant though it is suggestive $(r=+0.41)$. These results are in harmony with the known clinical relationship between scarlet fever and both rheumatic fever and acute nephritis. The puerperal sepsis values show a close correspondence with those of rheumatic fever and acute nephritis, all the coefficients being of the "highly significant" level. This rather striking 
result would seem to extend to a wider field the accepted relationship of rheumatic fever and acute nephritis to streptococcal infection. The correlations between rheumatic fever and stillbirth, and between acute nephritis and stillbirth, are all significant or highly significant. Moreover, the correlation of puerperal sepsis and stillbirth gives a highly significant coefficient $(+0.80)$, which is greater than that previously shown between eclampsia and stillbirth $(r=+0.77)$.

In Table III the regional death rates for nephritis in 1932-41 are given. These are average rates-that is to say, arithmetic means of the rates at $0-4,5-14$, and

TABLE III.-Regional Death Rates in England and Wales

\begin{tabular}{|c|c|c|c|c|c|}
\hline \multicolumn{4}{|c|}{ Region } & $\frac{\begin{array}{c}\text { Nephritis 0-44 Years } \\
\text { per Million Living, } \\
1932-41\end{array}}{1}$ & $\begin{array}{l}\text { Eclampsia per } 1,000 \\
\text { Live Births and Still- } \\
\text { births, } 1939-46\end{array}$ \\
\hline $\begin{array}{l}\text { Greater Lon } \\
\text { Remainder } \\
\text { North I } \\
\text { North II } \\
\text { North III } \\
\text { North IV } \\
\text { Midland I } \\
\text { Midland II } \\
\text { East . } \\
\text { South-west } \\
\text { Wales I } \\
\text { Wales II }\end{array}$ & $\begin{array}{c}\text { ndon } \\
\text { of } \mathbf{S . E .} \\
\ldots \\
\ldots \\
\ldots \\
\ldots \\
\ldots \\
\ldots \\
\ldots \\
\ldots \\
\ldots\end{array}$ & $\begin{array}{l}\ldots \\
\ldots \\
\cdots \\
\cdots \\
\cdots \\
\cdots \\
\therefore \\
\therefore\end{array}$ & $\begin{array}{l}\ldots \\
\ldots \\
\ldots \\
\ldots \\
\cdots \\
\cdots \\
\cdots \\
\cdots \\
\ldots\end{array}$ & $\begin{array}{l}49 \cdot 2 \\
44 \cdot 0 \\
73 \cdot 9 \\
57 \cdot 0 \\
65 \cdot 9 \\
68 \cdot 5 \\
61 \cdot 3 \\
59 \cdot 9 \\
43 \cdot 8 \\
53 \cdot 8 \\
80 \cdot 4 \\
77 \cdot 6\end{array}$ & $\begin{array}{l}0.42 \\
0.54 \\
0.64 \\
0.60 \\
0.55 \\
0.55 \\
0.56 \\
0.55 \\
0.52 \\
0.68 \\
0.77 \\
0.82\end{array}$ \\
\hline
\end{tabular}

Coefficient of correlation of columns 1 and $2=+0 \cdot 71$. Coefficient of correlation of column 2 and column 6 of Table $I=+0.61$.

15-44 years. Mortality from eclampsia is represented by the average annual rates calculated from deaths assigned to the puerperal toxaemias in the years 193946. The difference in the two periods of years, which is of little consequence, arises from the fact that relevant data of the same periods are not at hand. In the correlation of these two columns $r=+0.71$, a highly significant figure. The coefficient between puerperal sepsis (1932-7) and eclampsia (1939-46) is +0.61 , and is significant.

The association of high rheumatic fever and nephritis rates with high mortality from the streptococcal infections coincides with the seasonal experience of these conditions (Buchan, 1950b) and might have been expected, but the broad correspondences between stillbirth and rheumatic fever, nephritis, scarlet fever, and puerperal sepsis appear to raise the question of the relationship of streptococcal infection to stillbirth. Are unexplained stillbirths the effect, like rheumatic fever, of a factor associated with susceptibility to streptococcal infection? Here is a problem intertwined with social and environmental complexities of which the present limited analysis takes no account. But the general picture suggests, though it does not prove, that streptococcal infection plays a part in eclampsia and stillbirth-an aspect which seems worthy of further research.

\section{Summary}

In view of the possible relationship between eclampsia and both acute nephritis and rheumatic fever, the regional distribution in England and Wales of mortality from these diseases and from scarlet fever, puerperal sepsis, and stillbirth is considered.

Eclampsia and stillbirth have a similar regional distribution and are in frequent association clinically.

If heart disease mortality at 5-14 and 15-24 years is used as an index of rheumatic fever, and nephritis mortality in the same age groups as an index of acute nephritis, a close correspondence between the regional distribution of these two diseases is revealed.
The values for rheumatic fever and acute nephritis correlate fairly well with the scarlet fever death rates at $0-4$ years, and a direct relationship of rheumatic fever and acute nephritis with puerperal sepsis is clearly indicated. The coefficients between rheumatic fever mortality and stillbirth and between acute nephritis mortality and stillbirth are significant or highly significant. Puerperal sepsis is closely correlated with stillbirth, a result which points to the need for further inquiry into this aspect of the problem of stillbirth.

A close correspondence also exists between the regional variations of mortality from eclampsia, from nephritis, and from puerperal sepsis, a circumstance which, along with the other relationships indicated, would seem to support the use of cortisone in toxaemia of pregnancy, as well as in other diseases suspected of being streptococcal allergic disorders.

\section{REFERENCES}

Buchan T. W. (1950a). British Medical Journal, 2, 22.

Buchan, 1950b). Ibid., 1, 1268

Knowelden, J. (1949). Brit. J. soc. Med., 3, 29.

Moore, H., et al. (1951). British Medical Journal, 1, 841.

\section{Medical Memorandum}

\section{Total Gastric Polyposis With Malignant Changes}

In the routine clinical practice of a general hospital gastric polyposis is encountered somewhat infrequently, but assumes importance by virtue of the twin complications of malignancy and recurrent haemorrhage.

Menetrier (1888) was among the earlier observers to comment on the tendency to malignant change, but it was Quain (1857) who placed on record the first instance in which the diagnosis was made during life, in the case of a girl of 19, by the presence of a tumour the size of a chestnut in the patient's vomit.

The rarity of the condition may be appreciated from the findings of two series of necropsies : in the one, Stewart (1929) at Leeds noted 47 cases of gastric polyposis in a study of 11,000 cases $(0.43 \%)$; while in the second, Lawrence (1936), at the Cook County Hospital, U.S.A., observed 50 in 7,000 examinations $(0.71 \%)$.

The frequency of malignant change recorded by different observers may be seen by reference to the accompanying Table. In terms of age and sex, the incidence of gastric polyposis is greater in males above

\begin{tabular}{|c|c|c|c|}
\hline Author & Year & $\begin{array}{c}\text { Cases of Gastric } \\
\text { Polyposis }\end{array}$ & $\underset{\%}{\text { Malignancy }}$ \\
\hline 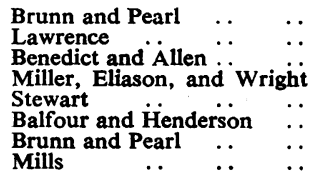 & $\begin{array}{l}1943 \\
1936 \\
1934 \\
1930 \\
1929 \\
1927 \\
1926 \\
1922-3\end{array}$ & $\begin{array}{l}41^{*} \\
50 \\
17 \\
23 \\
47 \\
57 \\
84 \\
19\end{array}$ & $\begin{array}{r}51 \cdot 0 \\
18 \cdot 0 \\
41 \cdot 2 \\
35 \cdot 0 \\
28 \cdot 0 \\
3 \cdot 5 \\
12 \cdot 0 \\
20 \cdot 0\end{array}$ \\
\hline
\end{tabular}

* Includes four cases in which data regarding malignancy were lacking.

50 years of age, in the proportion of 9 to 4 (Lawrence, 1936) or 2 to 1 (Chamberlin, 1938).

Symptoms are not as a rule typical, and may be absent if the polypi are situated away from the pylorus (Spriggs, 1942). When present, epigastric pain and vomiting in relation to meals may be conspicuous, due to the prolapse of polypi through the pylorus with sequential intermittent obstruction. Anorexia is common, usually in association with achlorhydria, whose constancy has 